\title{
Study on the Learning Thoughts of Zhang Zi from ShixueGuifan
}

\author{
Luyao Ma \\ Journal Editorial Department, Sichuan University of Arts and Science, Dazhou, China \\ Email: 2867195667@qq.com
}

How to cite this paper: Ma, L.Y. (2019) Study on the Learning Thoughts of Zhang Zi from ShixueGuifan. Open Access Library Journal, 6: e5651

https://doi.org/10.4236/oalib.1105651

Received: July 29, 2019

Accepted: August 12, 2019

Published: August 15, 2019

Copyright $\odot 2019$ by author(s) and Open Access Library Inc.

This work is licensed under the Creative Commons Attribution International License (CC BY 4.0).

http://creativecommons.org/licenses/by/4.0/

\begin{abstract}
Through the analysis of Zhang Zi's ShixueGuifan, this paper combs the learning ideas contained in the ShixueGuifan from four dimensions: learning purpose, learning content, learning methods and learning attitude.
\end{abstract}

\section{Subject Areas}

Education

\section{Keywords}

Zhang Zi, ShixueGuifan, Learning Thoughts

\section{Introduction}

Zhang Zi (1153-1235) [1], a famous scholar in the mid-Southern Song Dynasty, wrote a lot of works in his life, but many of them passed away. Among them, ten volumes of Nanhu Collection and forty volumes of ShixueGuifan were widely circulated (Figure 1). The study of Zhang Zi mainly focuses on the textual research of his life [2] and death year and the achievement of his poetry in academia [3]. The research on ShixueGuifan is mainly focused on the main contents and literature value of the book [4]. The academies are still lack of research on Zhang's works, life and thoughts, and there are many areas for further study. Among them, the study of Zhang's educational thoughts from the ShixueGuifan is a problem that can be explored.

There are internal and external reasons for Zhang Zi's compilation of the ShixueGuifan. The external main reasons are as follows: Firstly, in the Song Dynasty, the Chinese society completed the transformation from the family system of the gate-lords in Wei and Jin Dynasty to the non-hereditary family system. Through the imperial examination system, ordinary scholars could realize the 


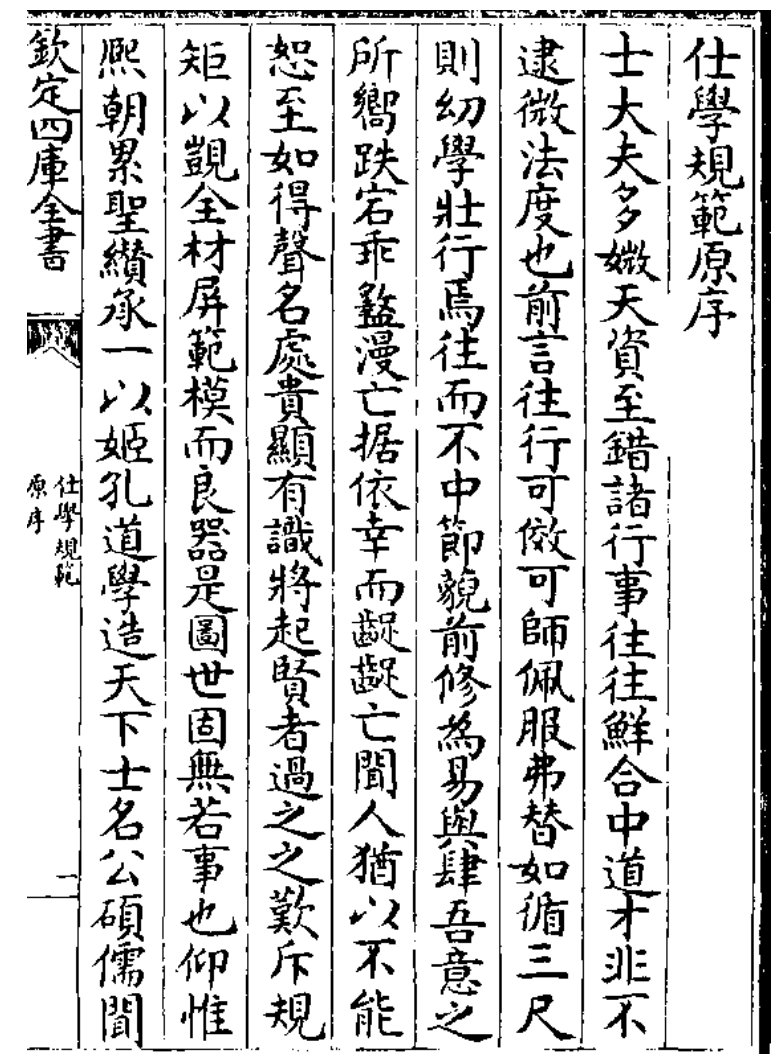

Figure 1. ShixueGuifan (Source: SikuQuanshu).

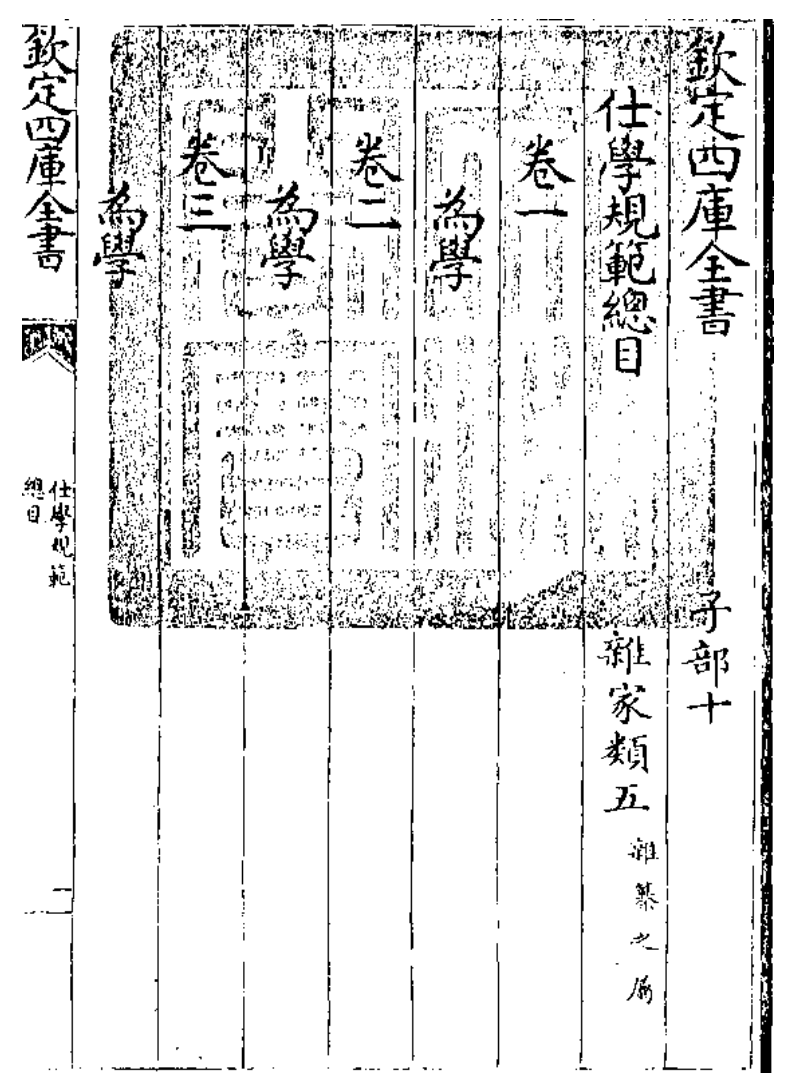

Figure 2. ShixueGuifan (Source: SikuQuanshu). 


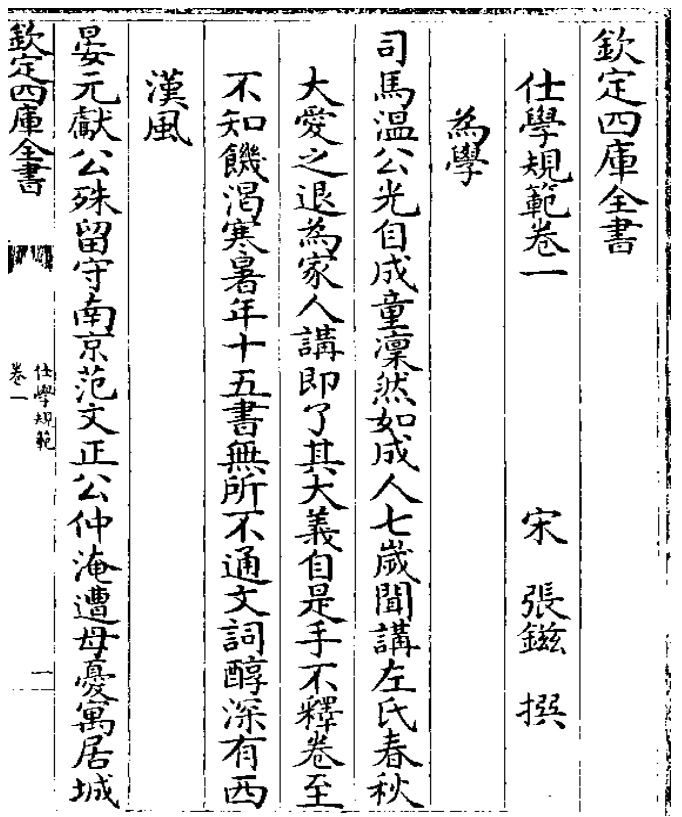

Figure 3. ShixueGuifan (Source: SikuQuanshu).

rise of a new family through personal struggle. But in order to achieve the sustained prosperity of the new big clan, it needs a lot of talented people from each generation of the family. Under this background, a lot of family precepts were produced in the official family to train and guide the family descendants. Secondly, private schools flourished in the Song Dynasty, and academies were numerous. These private schools also established norms to guide students to learn to be human beings. Thirdly, with the rapid increase in the number of imperial examinations and the prosperity of the book publishing industry in the Song Dynasty, there are also many books on the market, such as guiding learning, seeking official positions, cultivating one's moral character, and creating poetry and prose. The internal reason is that Zhang's great-grandfather was a generation of famous generals, but under the influence of the policy of emphasizing literature and despising military force in the Southern Song Dynasty, he decided to change his family style to literary style. Zhang's grandfather, Zhang Zihou, and his father, Zhang Zongyuan, developed very well on literary road. By the time of Zhang's generation, the family's conversion from martial arts to prose had been completed. Therefore, efforts should be made to cultivate the cultural accomplishment of the descendants of the family. Under the influence of internal and external factors, Zhang Zi extracted 100 kinds of books related to the Song Dynasty, and compiled 40 volumes of the ShixueGuifan according to six categories: learning, practice, being an official, moral characters, writing articles and poetry.

Volumes 1 to 3 were about "Learning" (Figure 2 \& Figure 3), which mainly explained the way of learning, and to some extent reflects Zhang's educational ideas and propositions. Therefore, this paper intends to explore Zhang's learning thoughts through the analysis of the part of "Learning". 


\section{Learning Thoughts of ShixueGuifan}

Through sorting out the ShixueGuifan, it involves the following aspects: first, why to learn, including the essence and purpose of learning; second, what to learn, the question of learning content; third, how to learn, mainly including learning methods, learning attitudes, learning approaches; fourth, why to learn, including the essence and purpose of learning; The fifth is the factors that affect learning. These aspects are discussed separately as follows.

\subsection{Purpose of Learning}

The first problem of learning is why to learn, that is, what kind of person one wants to become through learning. In the Confucian educational thought system, the primary purpose of learning is to learn to be a gentleman with both moral characters and wisdom. There are six items on the purpose of learning in the ShixueGuifan. Zhang Zi put forward three learning purposes on the pretext of others: cultivation of morality and intelligence; practical application; explore the nature of things.

\subsubsection{Cultivation of Morality and Intelligence}

The fundamental purpose of learning is to change learners at the social and physiological levels to meet the needs of specific society. Zhang $\mathrm{Zi}$ advocated that the mental training of learners should include moral cultivation at the social level and intellectual enhancement at the physiological level. The former can be attributed to Confucius' advocacy of learning to be a gentleman, while the latter involves the development and promotion of human intelligence to meet the needs of other social activities. In the ShixueGuifan, Zhang Zi quoted Sima Guang's Sushuiyushu and emphasized that "Learning lies in the cultivation of mind. Even if you have learned a lot of knowledge, but your morality and intelligence have not been cultivated, it cannot be called learning."

\subsubsection{Practical Application}

The ultimate goal of learning is to practice in real life, which is also one of the core of Confucian learning concept. That is to say, through learning, learners can improve their morality and intelligence, which ultimately play a role in solving a specific matter in real life. In the ShixueGuifan, Zhang Zi quoted the words of Zhang Jiucheng emphasized that "The purpose of learning is not only to succeed in examinations and in being an official, but also to accomplish everything in daily life." At the same time, Zhang Jiucheng further emphasized the importance of practical application in learning through the conversation between Confucius and his students. Zhang Jiucheng said, "Confucius and his students' knowledge is not only expressed in language, but also reflected in daily practice."

\subsubsection{Explore the Nature of Things}

In Confucianism, it is also an important learning purpose to explore the nature 
of things through learning. Only by studying hard to explore the nature of things, can we understand and master the operation law of things and society. In the ShixueGuifan, Zhang Zi quoted Pu Dashou's Pu Shi Man Zhai Lu and said, "Learning must first explore the nature of things." The reason why we should take it as the basis and premise of learning is that we can't fully understand things without understanding the nature of things, and we can't make good use of and practice things without fully understanding them.

The purpose of learning advocated by Zhang Zi reflects the view of learning purpose of Neo-Confucianism scholars in Song Dynasty. Although there are fewer entries about learning purpose in the ShixueGuifan, it can be concluded that Zhang advocates the system of learning purpose: to explore the nature of things through learning, to realize the cultivation of learners' morality and intelligence on this basis, and finally to apply it to the specific affairs of real social life.

\subsection{Learning Content}

Learning goals are achieved by learning certain contents through certain learning methods. There are more than ten items in Zhang Zi's ShixueGuifan which all involve the content of learning. Through sorting out these items, it is found that the learning contents he advocated mainly include Confucianism, history and the Various Scholars and the Hundred Schools.

\subsubsection{Confucianism}

Zhang $\mathrm{Zi}$ believes that the traditional Confucian classics should be the main content of learning. Confucianism in Chinese cultural tradition mainly refers to Confucianism represented by Confucius. The development of Confucianism in China to the Southern Song Dynasty, was finalized as the "Thirteen Classics", which also became the main content of learning advocated by Zhang Zi. Zhang Zi quoted Ouyang Xiu's Luling Collection to emphasize the importance of "the book of saints", believing that "the book of saints is as high as the sun and the moon and shines all over the earth." But, "If there is no wise teacher, then the learner should regard the classics as a teacher."

\subsubsection{History}

In the Song Dynasty, the main purpose of most learners' learning was to take the imperial examinations and then become officials. The main content of the imperial examinations in the Song Dynasty was Confucian classics and literary creation, but not enough attention was paid to history. However, in Zhang's view, Confucianism and historiography play different roles for learners and cannot be replaced by each other.

\subsubsection{The Various Scholars and the Hundred Schools}

In addition to Confucian classics and history, Zhang Zi believed that the Various Scholars and the Hundred Schools were also the contents that learners should learn, but their importance and priority were not as important as Confucian 
classics and history. Zhang Zi borrowed Lü Benzhong's words and thought that "all the strengths of the Various Scholars and the Hundred Schools should be used by us", so "besides Confucian classics and history, the works of the Various Scholars and the Hundred Schools also need to be read." [5] However, Zhang also found that in addition to training officials, applied talents needed in all fields of society must be trained through learning. Therefore, he expressed his recognition of Applied Learning by affirming the educational practice of $\mathrm{Hu}$ Yuan, a famous educator in the Southern Song Dynasty.

From the above analysis, we can see that the content of learning advocated by Zhang $\mathrm{Zi}$ is more comprehensive, which emphasizes not only the study adapted to the imperial examination, but also the various knowledge of history, the Various Scholars and the Hundred Schools, and daily application.

\subsection{Learning Methods}

Learning methods determine learning effect. Chinese ancients realized this problem at a very early time and put forward many effective learning methods. Zhang Zi excerpted 26 items about learning methods in the ShixueGuifan. This shows that Confucianism and Zhang Zi in Song Dynasty attached great importance to learning methods. By sorting out these 26 items, it is found that the learning methods he advocated mainly include the following seven kinds.

\subsubsection{Laying a Solid Foundation}

Zhang $\mathrm{Zi}$ believed that if we want to achieve great success in learning, we must lay a solid foundation. He quoted Cheng Yi and Cheng Hao by saying, "Learning is like building a high-rise building, which needs to be firmly grounded." [5] $\mathrm{He}$ also took Confucius as an example to demonstrate the importance of laying a solid foundation for learning. Confucius was studying before 63 years old and was an official in many countries. He laid a solid foundation for his later creation. Therefore, from 63 years old, he had sorted out the great and far-reaching work Six Classics.

\subsubsection{Learning in Order}

In Chinese learning thought, sequential learning is an important learning method. Zhang Zi cited three documents to illustrate the importance of this method. The learning order of the classics was: the Analects of Confucius, Mencius and the Six Classics. Among the Six Classics, shijing, chunqiu, zhouyi, shangshu were the first. However, learning classics was not the purpose, the cultivation of learners' spirits and behavior was the real purpose. Based on this, Zhang Zi believed that before learning classics, the attitude of respectful learning and practice in life should be the first priority.

\subsubsection{Thinking More}

Confucius said, "Learning without thinking is futile" [6]. In the process of learning, thinking more as an important learning method was emphasized by Zhang $\mathrm{Zi}$ in the ShixueGuifan. By quoting Cheng Yi's words, "we believe that 
learning must be thought if we want to gain. "Learning classics was like this, learning history could not be separated from thinking, "Reading history books, we can not only remember the historical facts, but must think about the truth behind the historical facts." [5] At the same time, it is pointed out that learning should not only stay on the surface of the text, but also understand the truth hidden behind the text by thinking.

\subsubsection{Discussing with Each Other}

Since Confucius used the method of mutual discussion on a large scale, mutual discussion has become an important learning method in China. Zhang $\mathrm{Zi}$ also attached great importance to this method of learning. He quoted Zhang Zai and Yin Zhuo's related discussions and believes that "if there is no progress in learning, only more discussions with friends can make progress." [5] The reason why discussion among friends has great benefit is that "in learning, the teacher is only a guide to the beginning, and at the same time, the teacher is mostly serious. Only friends can discuss the details of the problem in their leisure time." Therefore, learning "needs the help of friends, often discuss with friends, over time, learning is improved."

\subsubsection{Reading Aloud}

How to read books silently or aloud is also a question of learning methods discussed by ancient Chinese. Zhang Zi emphasized the important value of recitation as a learning method through the examples of Sima Guang, a famous scholar in the Song Dynasty. Sima Guang said: "while reading we must read aloud, so that we can understand the meaning behind the text." [5] But recitation also requires methods: clear words, the last word of each sentence must be stressed. At the same time, repeated reading is necessary. Huang Anzhong once said "in the morning we must read the classics 500 times, after lunch we must read the history book 100 times, and in the evening we must read the works of ancient philosophers 300 times".

\subsubsection{Asking More Questions}

In the process of learning, it is an important learning method to ask others for advice when encountering unknown places. Zhang $\mathrm{Zi}$ also advocated method of asking more questions in the ShixueGuifan. The reason for emphasizing this method is that people at that time generally had a concept: being ashamed of asking people. Therefore, Zhang Zi quoted Zhang Zai and Xie Liangzuo's viewpoints and emphasised that one should not be ashamed to ask questions in learning.

\subsubsection{Learning in Practice}

Zhang $\mathrm{Zi}$ inherited the view of the ancient that learning needs to be carried out from both books and practice and emphasized the method of learning in practice. By quoting Cheng Yi and Cheng Hao's views on truth and common sense, it is believed that knowledge of truth can only be acquired from practice. At the same time, he emphasized that learners can gain something not only through reading, but also through practice. 


\subsection{Learning Attitude}

Learning attitude generally refers to a relatively stable psychological tendency of students towards learning and its learning situation. It can usually be judged and explained from the students' attention to learning, emotional state and will state. In order to achieve the goal of learning, besides learning appropriate content and adopting correct learning methods, good learning attitude is also indispensable. As for learning attitude, it is also the focus of Zhang Zi's attention in the ShixueGuifan. Eighteen relevant materials are extracted. The main learning attitudes he advocated were as follows:

\subsubsection{Being Fond of Learning}

Being fond of learning as a psychological tendency has a positive impact on improving learning effect. Although Zhang did not explore the correlation between the two from the perspective of psychology, he advocated this learning attitude through the example of Sheng Du. Sheng Du liked reading, and he always read when he was at home. His family advised him to take a break, but he said, "I like reading, and I don't think it's a tiring thing."

\subsubsection{Studying Hard}

Generally speaking, learning requires great physical and spiritual efforts of learners. Only by persevering in hard learning can certain achievements be achieved. In the ShixueGuifan, Zhang Zi emphasized the importance of hard learning for learning. The value of painstaking study was illustrated by the examples of Xiang Lun, Li Xuzhou, Hu Ying and Wang Deshen. Xiang Lun studied hard day and night, reading and memorizing thousands of words every day. $\mathrm{Li}$ Xuzhou was poor and could not afford to buy books. When he wanted to read, he borrowed books from others to copy them and read them at night. When Hu Ying was young, he studied hard in Mount Tai and stayed up all night.

\subsubsection{Concentration}

Learning requires concentration, not half-heartedness. Zhang Zi believed that concentration was a very important learning attitude. If one did not concentrate on his study, he would turn over like a waterwheel and never stop. In that case, when he studied, he would learn everything, but he would not learn it well. He quoted Cheng Yi by saying that "learners should be dedicated in the process of learning, only when they understand what they have learnt, can they gain."

\subsubsection{Never Being Impatient}

Learning requires calmness, not impatience. Zhang Zi believed "Learners must calm down and never be impatient. They should read and experience the contents carefully so as to gain something. In a hurry, you can't get the main road.”

\subsubsection{Being Persistent}

Learning is a long-term process, which requires arduous efforts. Only long-term perseverance can ultimately achieve results. Zhang said "The relationship be- 
tween intellectuals and learning is like peasants and farming. If peasants do not farm, there will be no food to eat. If they do not, they will starve to death. Can intellectuals not study for a day?" [5] Here, through Cheng Yi's book, Zhang Zi believed that learners should study unremittingly every day.

\section{Conclusion}

In ShixueGuifan, Zhang Zi put forward systematic learning thoughts from four aspects: learning purpose, learning content, learning method and learning attitude by quoting others' comments. These learning thoughts are not only his inheritance of predecessors, but also his personal experience. At present, it still has some value for us.

\section{Conflicts of Interest}

The author declares no conflicts of interest regarding the publication of this paper.

\section{References}

[1] Wang, X.L. and Wang, Z.P. (2002) Annual Examination of Zhang Zi's Birth and Death. Literary Heritage, 1, 60.

[2] Zeng, W.G. (2010) The Chronicle of Zhang Zi. People's Publishing House, Beijing.

[3] Zeng, W.G. (2011) South Lake Collection. Literary Heritage, 5, 141-143.

[4] Li, Z.S. (2013) Study of Shixue Guifan. Henan University, Zhengzhou.

[5] Zhang, Z. (1176) Shixue Guifan, the Edition of Song Dynasty.

[6] Confucius (2016) Analects. Zhonghua Book Company, Beijing. 